\title{
Medidas tributarias anticrisis de España. Análisis específico de la amnistía fiscal
}

\author{
Miguel Ángel Sánchez Huete*
}

\begin{abstract}
RESUMEN
Ante la crisis financiera global que vivimos el gobierno español ha efectuado -y efectúa-numerosas modificaciones normativas que afectan a los ingresos y gastos públicos. En tal contexto destaca la medida extraordinaria de la amnistía fiscal introducida por el Real Decreto-Ley 12/2012, de 30 de marzo. Con ella se pretende allegar recursos públicos estableciendo una singularidad en la tributación de bienes no declarados. La amnistía fiscal es una institución marcada por el sentido de la urgencia y la necesidad de recursos derivada de la crisis económica. Pero ante tal regulación los interrogantes y cuestiones se agolpan: ¿qué es la amnistía fiscal?. ¿afecta al principio de igualdad tributaria?, ¿cuáles son sus consecuencias punitivas?
\end{abstract}

Amnistía fiscal - regularización fiscal -blanqueo de capitales

\section{Anti-crisis tax measures in Spain: A specific analysis of tax amnesty}

\begin{abstract}
The Spanish government has made - and continues to make - numerous policy changes affecting public revenues and expenditures in response to the global financial crisis. Among them is the extraordinary measure of tax amnesty introduced by Royal Decree 12/2012, of March 30, which seeks to increase public income by establishing a special rule for public taxation of undeclared assets. The tax amnesty is an institution marked by the sense of urgency and the need for resources resulting from the economic crisis. However, such regulation raises certain questions and issues: What is tax amnesty? Does it affect the principle of tax equity? What are the punitive consequences?
\end{abstract}

Tax amnesty - tax adjustment - money laundering

* Licenciado y Doctor en Derecho, Profesor de Derecho Financiero y Tributario, Facultad de Derecho, Universidad Autónoma de Barcelona, España. Correo electrónico: miguelangel.sanchez@uab.es

Artículo recibido el 7 de marzo de 2013 y aceptado para su publicación por el Comité Editorial el 29 de mayo de 2013. 


\section{Medidas financieras de la CRisis. El CONTEXto}

$\mathrm{L}$ a crisis financiera global que vivimos, en particular en la Unión Europea, enmarca su singularidad en la generalidad de sus efectos y la necesidad de intervención de los Estados ante la disfunción de los mercados. En la primera década de este siglo -se señala habitualmente el año 2008- se ha generado una más de las crisis propias del capitalismo. Su proximidad nos impide ver sus dimensiones y nos dificulta el entendimiento y la comprensión completa de sus causas. Posiblemente resulte un reflujo a las ideas imperantes del neoliberalismo asentadas en la no intervención del Estado en la regulación y control de los mercados; o en otros términos, la crisis tenga como causa la acción desmedida de los mercados, en concreto, del mercado financiero. En el origen de la crisis destaca Cazorla Prieto el papel del sector financiero, cuyo crecimiento ha estado apoyado en la sobrevaloración de los activos y en la suposición de que su precio iba a seguir aumentando, junto a unos organismos públicos reguladores que no han intervenido ni supervisado ${ }^{1}$.

La crisis conlleva unos claros efectos financieros en el Estado: una pérdida de recaudación, tanto de los impuestos directos como indirectos, y un aumento de las necesidades sociales, derivadas del desempleo y demás prestaciones. En tal panorama de contracción de ingresos se adopta una medida tributaria que busca aumentar de manera extraordinaria la recaudación de fondos públicos: la amnistía fiscal. El Real Decreto Ley 12/2012, de 30 de marzo, por el que se introducen diversas medidas tributarias y administrativas dirigidas a la reducción del déficit público, regula la que denomina declaración tributaria especial, una medida que permite regularizar la situación jurídica de quienes no habían declarado puntualmente sus bienes. Como contexto y marco de nuestro objeto de estudio, resulta de interés analizar algunos de los principales ítems que han configurado las medidas fiscales y presupuestarias adoptadas por el gobierno español con motivo de la crisis.

Delimitar las medidas financieras realizadas por el Estado español resulta una tarea ardua. Ello es así, no tan solo por las múltiples medidas adoptadas, sino por la problemática propia que presenta la descentralización del Estado y las notables facultades legislativas del Gobierno.

Por un lado, existe una gran profusión de disposiciones normativas de diverso rango (desde una reforma constitucional a múltiples modificaciones reglamentarias) y ámbito (fiscal, laboral, financiero, gasto público...). Tales modificaciones se dan, además, en diversos niveles de gobierno con poder normativo -Unión Europea, Estado, comunidades autónomas y entidades locales-. Todo ello origina una concurrencia normativa, tanto vertical, dominada por relaciones de jerarquía, como horizontal, en donde los criterios de competencia son determinantes. Normativamente la crisis incide en una multiplicidad de ámbitos materiales cada uno de ellos con diverso grado de competencias entre las diversas entidades. No cabe obviar que la autonomía financiera de los entes territoriales

\footnotetext{
${ }^{1}$ Cazorla, L.M., Crisis económica y transformación del Estado, Aranzadi, Navarra, 2009, p. 34.
} 
dota de complejidad y dificulta, en ocasiones, la adopción de políticas coherentes anticrisis. Así, no es extraño que, junto a medidas del Estado que buscan incrementar los ingresos públicos, existan normas autonómicas con visión contrapuesta. En tal tesitura, no es la existencia de autonomía el problema, sino la falta de coordinación y consenso en el análisis y medidas a adoptar por los diversos niveles de gobierno.

Por otro lado, al anterior panorama se le suma el hecho de que la mayoría de las medidas adoptadas se han llevado a cabo por el Poder Ejecutivo a través de una legislación de urgencia (Decretos-Ley). Ello comporta una normativa extraordinariamente veloz y cambiante que dificulta un conocimiento preciso. También, y derivado de tal celeridad, se observa en no pocas ocasiones una redacción escasamente técnica.

Para abordar la problemática de la crisis se han dictado múltiples normas que afectan a diversos sectores: laboral, seguridad social, mercantil, administrativo... Muchas de tales disposiciones normativas poseen un contenido heterogéneo cuya única lógica de agrupación es combatir los efectos de dicha crisis. Así, a la vez que tratan aspectos relativos a la tributación, o al gasto público, se adoptan medidas en otros ámbitos como el mercantil o laboral.

Aglutinar las grandes líneas de intervención normativa no resulta una tarea fácil, si bien la legislación anticrisis y las materias reguladas se han vinculado a las diversas causas o consecuencias que han originado la crisis: a) el boom inmobiliario y la titulización por las entidades de crédito de los activos financieros con riesgo, b) la falta de fluidez del crédito en el sector productivo, y c) el desequilibrio de las cuentas públicas. Así se destinan esfuerzos por financiar -avalar-y reestructurar las entidades de crédito; se inyecta liquidez en el sector económico mediante la realización de obras públicas o facilitando el acceso al crédito; se establecen medidas ante las situaciones de impagos y ejecuciones -concursos, ejecuciones hipotecarias...-; o se establecen medidas de austeridad en el sector público a través de conformar un principio económico de estabilidad presupuestaria concreto y exigible. Tal panorama normativo, profuso y movible, nos podría llevar a hablar de un cierto Derecho de la crisis, en la medida que se substantive el fenómeno crisis como realidad social singular que precisa de normas específicas cuya finalidad es paliar o enfrentarse a sus efectos. Este Derecho abarcaría diversos ámbitos normativos en el que destacaría el análisis de la actividad financiera, tanto privada -objeto del Derecho Mercantil- como pública -objeto del Derecho Financiero-, y que pudiera estar aglutinado por principios propios.

Son numerosas las normas financieras y medidas adoptadas, si bien podríamos sintetizar dos grandes orientaciones ${ }^{2}$ :

\footnotetext{
${ }^{2}$ A este respecto, y atendiendo al año de su emisión, hemos de considerar la siguiente normativa financiera: $1^{\circ}$. En el 2008 se dictó el Real Decreto-Ley 2/2008, de 21 de abril, de medidas de impulso a la actividad económica. El Real Decreto-Ley 5/2008, de 3 de octubre, por el que se autoriza a la Administración General del Estado a formalizar un contrato de garantía con el Banco Europeo de Inversiones y se amplía el límite para el otorgamiento de avales fijado en el artículo 54 de la Ley 51/2007, de 26 de diciembre, de Presupuestos Generales del Estado para 2008, el Real Decreto-Ley 6/2008, de 10 de octubre, por el que se crea el Fondo para la Adquisición de Activos Financieros, el Real Decreto-Ley 7/2008, de 13 de octubre, de Medidas Urgentes en Materia Económico-Financiera en relación con el Plan de Acción Concertada de
} 
En primer lugar, la existencia de diversos ámbitos sobre los que se ha intervenido: el mercado financiero, la economía productiva y las cuentas públicas. De ahí que quepa hablar de varias crisis, de diversos mercados y ámbitos, y que precisan, consiguientemente, de intervenciones diferenciadas. Así se ha puesto de relieve una primera crisis del mercado financiero, otra de la economía productiva, e incluso cabe hablar de una crisis de las cuentas públicas de los Estados. El reconocimiento de la pluralidad de crisis permite evidenciar su complejidad para un tratamiento más eficaz, pero también calibrar el sentido de las diversas medidas adoptadas. Se trata de una crisis de crisis, o una crisis sistémica de amplio espectro, que los mercados se ven incapaces de atajar por sí solos y ha de intervenir el Estado.

En segundo lugar, la intervención en tales crisis se ha efectuado mediante medidas financieras que afectan no tan solo a los ingresos y a los gastos privados, sino sobre todo

los Países de la Zona Euro, el Real Decreto-Ley 9/2008, de 28 de noviembre, por el que se crean un Fondo Estatal de Inversión Local y un Fondo Especial del Estado para la Dinamización de la Economía y el Empleo y se aprueban créditos extraordinarios para atender a su financiación, el Real Decreto-Ley 10/2008, de 12 de diciembre, por el que se adoptan medidas financieras para la mejora de la liquidez de las pequeñas y medianas empresas, y otras medidas económicas complementarias, y la Ley 4/2008, de 23 de diciembre, por la que se suprime el gravamen del Impuesto sobre el Patrimonio, se generaliza el sistema de devolución mensual en el Impuesto sobre el Valor Añadido, y se introducen otras modificaciones en la normativa tributaria. $2^{\circ}$. En el año 2009 el Real Decreto-Ley 3/2009, de 27 de marzo, de medidas urgentes en materia tributaria, financiera y concursal ante la evolución de la situación económica, el Real Decreto-Ley 5/2009, de 24 de abril, de medidas extraordinarias y urgentes para facilitar a las entidades locales el saneamiento de deudas pendientes de pago con empresas y autónomos, y el Real Decreto-Ley 13/2009, de 26 de octubre, por el que se crea el Fondo Estatal para el Empleo y la Sostenibilidad Local. 3. En el 2010 el Real Decreto-Ley 5/2010, de 31 de marzo, por el que se amplía la vigencia de determinadas medidas económicas de carácter temporal, el Real Decreto-Ley 6/2010, de 9 de abril, de medidas para el impulso de la recuperación económica y el empleo, el Real Decreto-Ley 8/2010, de 20 de mayo, por el que se adoptan medidas extraordinarias para la reducción del déficit público, el Real Decreto-Ley 9/2010, de 28 de mayo, por el que se autoriza a la Administración General del Estado al otorgamiento de avales a determinadas operaciones de financiación en el marco del Mecanismo Europeo de Estabilización Financiera de los Estados miembros de la Zona del Euro, y el Real Decreto-Ley 13/2010, de 3 de diciembre, de actuaciones en el ámbito fiscal, laboral y liberalizadoras para fomentar la inversión y la creación de empleo. $4^{\circ}$. En el 2011 el Real Decreto-Ley 5/2011, de 29 de abril, de medidas para la regularización y control del empleo sumergido y fomento de la rehabilitación de viviendas, el Real Decreto-Ley 8/2011, de 1 de julio, de medidas de apoyo a los deudores hipotecarios, de control del gasto público y cancelación de deudas con empresas y autónomos contraídas por las entidades locales, de fomento de la actividad empresarial e impulso de la rehabilitación y de simplificación administrativa, el Real Decreto-Ley 9/2011, de 19 de agosto, de medidas para la mejora de la calidad y cohesión del sistema nacional de salud, de contribución a la consolidación fiscal, y de elevación del importe máximo de los avales del Estado para 2011, el Real Decreto-Ley 13/2011, de 16 de septiembre, por el que se restablece el Impuesto sobre el Patrimonio, con carácter temporal, el Real Decreto-Ley 20/2011, de 30 de diciembre, de medidas urgentes en materia presupuestaria, tributaria y financiera para la corrección del déficit público y la modificación del art. 135 de la Constitución Española de 27 de septiembre de 2011. 5. En el 2012 el Real Decreto-Ley 3/2012, de 10 de febrero, de medidas urgentes para la reforma del mercado laboral, el Real Decreto-Ley 4/2012, de 24 de febrero, por el que se determinan obligaciones de información y procedimientos necesarios para establecer un mecanismo de financiación para el pago a los proveedores de las entidades locales, el Real Decreto-Ley 6/2012, de 9 de marzo, de medidas urgentes de protección de deudores hipotecarios sin recursos, y el Real Decreto-Ley 7/2012, de 9 de marzo, por el que se crea el Fondo para la financiación de los pagos a proveedores. 
a los públicos. De ahí que se hayan dictado múltiples normas para regular la materia tributaria (ingresos) y la presupuestaria (gastos). La intervención jurídica del Estado en la crisis ha sido importante, cuantitativa y cualitativamente; desde una reforma constitucional efectuada en un tiempo record de un es $^{3}$, a dictar una cuantía ingente de Decretos Ley de urgencia. El Decreto Ley se ha utilizado -y se utiliza- con una gran profusión, casi cada viernes (momento de la reunión del Consejo de Ministros) se acuerda un paquete de medidas que ven la luz a través de la legislación de urgencia. Con ello se pone de relieve el carácter usual, ordinario, de dicha medida extraordinaria, y se evidencia la primacía del papel del gobierno en la tarea legislativa, convirtiendo al Parlamento en una institución de ratificación y convalidación.

Contextualizada la problemática que afecta a los gastos e ingresos públicos procede centrar nuestro objeto, su perspectiva, y la finalidad que anima a las presentes páginas.

Nuestro objeto es el estudio de la amnistía fiscal: una medida destinada a obtener recursos públicos en el contexto de crisis económica que vive España. Esta primera afirmación, que ubica tal fenómeno, no puede llevar a ignorar los importantes interrogantes que la institución jurídica genera. La disposición adicional primera del Real Decreto Ley 12/2012, de 30 de marzo, regula la declaración tributaria especial que introduce lo que popularmente se ha denominado amnistía fiscal. Pero ¿qué es la amnistía fiscal y qué supone?

Para resolver tales cuestiones la perspectiva de análisis a adoptar es la propia del Derecho Tributario en que se inscribe, si bien habrá de tenerse en consideración las implicaciones punitivas existentes. Por consiguiente, la diversidad de los efectos jurídicos que se originan nos llevará, además de analizar en clave jurídico-tributaria la institución, a efectuar consideraciones de carácter punitivo. La finalidad principal del presente artículo es determinar la naturaleza, características y consecuencias de la amnistía fiscal. Enmarcado en las anteriores consideraciones procede verificar si su regulación se adecua al principio básico de imposición como es el de igualdad.

${ }^{3}$ Se realiza la reforma con carácter urgente, en apenas un mes, del artículo 135 de la Constitución Española. Dicho precepto establece el principio de estabilidad presupuestaria de manera expresa y afirma su vinculación a todas las Administraciones Públicas. Pone de evidencia dos condicionantes con las que nace: los compromisos con la Unión Europea y el contexto de crisis. El primer condicionante se pone de relieve al remitirse a las disposiciones de la Unión Europea, pues "El Estado y las Comunidades Autónomas no podrán incurrir en un déficit estructural que supere los márgenes establecidos, en su caso, por la Unión Europea para sus Estados Miembros". El segundo de los condicionantes se evidencia por el contexto en que tiene lugar, pues reitera una idea ya preexistente que resulta un mensaje claro a los mercados respecto de la deuda pública: su prioridad absoluta en el pago.

La reforma constitucional nace con un fuerte enfoque ideológico y coyuntural. Ideológico por cuanto plasma una concreta posición de los poderes públicos respecto de la acción económica. Todo ello teniendo en cuenta que la estabilidad económica garantiza una determinada relación entre ingresos y gastos pero no elimina el mal gasto, el gasto innecesario, ni tampoco sirve de garante para las necesidades sociales básicas. Coyuntural en tanto que parece auspiciada por las necesidades propias de la crisis en que vivimos. De ahí el carácter urgente de su reforma, aspecto que no deja de contrastar con la demora de su eficacia a partir del 2020. 


\section{2. ¿A QUÉ llamamos AMNISTÍ́A FISCAL?}

Delimitar el sentido de lo que es la amnistía fiscal pasa por reflexionar sobre su admisibilidad en el ordenamiento español y analizar su régimen. Tales aspectos nos permitirán sentar las bases para acotar su naturaleza y fundamento, obteniendo un sentido más acabado y complejo de dicha institución.

La amnistía carece de reconocimiento expreso en la Constitución española (en adelante también CE), únicamente se reconoce el derecho de gracia o indulto. Ahora bien, amnistía e indulto son conceptos diversos en su sentido, fundamento, y régimen. Por un lado, la amnistía supone una medida genérica que elimina la ilicitud de un conjunto de conductas, resulta el olvido - la amnesia, en consonancia a su etimología griega amnestía- del delito. Por otro lado, el indulto supone una medida concreta de perdón, con carácter individualizado de la pena impuesta, y aparece vinculado, sobre todo, a la administración de justicia ${ }^{4}$. Las diferencias son evidentes, en un caso se altera el ordenamiento jurídico y, en el otro, se evalúa individualmente el impacto de la pena.

La Constitución española reconoce expresamente el indulto estableciendo prevenciones respecto de los indultos generales y señala concretos límites a los mismos en el art. 87.3 y en el art. 102.3. No obstante, guarda silencio respecto de la amnistía, no establece prohibiciones ni límites a su concesión. A tenor de tal silencio, y sobre la base de que la amnistía supone una derogación retroactiva de la norma punitiva, sería admisible su inclusión según el tenor del art. 9.3 de la $\mathrm{CE}^{5}$. Dicho precepto afirma que "La Constitución garantiza [...] la irretroactividad de las disposiciones sancionadoras no favorables o restrictivas de derechos individuales [...]". Por consiguiente, resulta admisible la existencia de disposiciones punitivas o sancionadoras más favorables que tengan efectos retroactivos. En definitiva, no existe prohibición alguna para la existencia de amnistías, siempre que las normas que la establezcan posean el adecuado rango normativo en relación con la norma que modifiquen.

La figura de la amnistía se vincula al ámbito punitivo y posee una eficacia genérica, ya que supone alterar el ordenamiento jurídico, haciendo no sancionable la anterior conducta prohibida. Junto a la dimensión de exoneración de la responsabilidad punitiva cabe tener presente que el ordenamiento tributario admite la condonación de las deudas tributarias, siempre que una ley expresamente así lo determine -exart. 75 de la Ley 58/2003, de 17 de diciembre, General Tributaria (en adelante LGT)-.

En la expresión de amnistía fiscal utilizada se conjugan dos dimensiones diversas admitidas por el ordenamiento: la punitiva, de la que recibe tal designación y que supone la exención de responsabilidad de tal naturaleza; y el perdón o condonación de

\footnotetext{
${ }^{4}$ Define Linde Paniagua a indulto como "el acto mediante el que se atenúa o extingue la pena o sanción impuesta y otros efectos, sin que ello implique modificación alguna del ordenamiento sancionador que se aplicó al sancionado" (Linde, E., “Amnistía e indulto en la Constitución Española de 1978”, en Boletín Informativo del Departamento de Derecho Político e Internacional, 2. UNED, 1978-1979, pp. 65).

${ }^{5}$ Ver Linde, E., “Amnistía e indulto en la Constitución Española de 1978”, en Boletín Informativo del Departamento de Derecho Político e Internacional, 2. UNED, 1978-1979, pp. 57.
} 
la deuda tributaria que se efectúa para el caso de dar cumplimiento a lo previsto en una ley. Este último resulta del contexto de la regularización tributaria que se plantea con la amnistía fiscal.

Regularizar supone que el obligado realiza conductas tendentes a subsanar o corregir su situación tributaria anterior para que resulte acorde a la legalidad. La regularización puede efectuarse de distintas formas - presentando declaración o autoliquidación-; con diversos efectos -según exista o no ingreso, se efectúe extemporáneamente o medie requerimiento administrativo-; y con diversa extensión y contenido -rectificando anteriores declaraciones o subsanando su ausencia-. La forma genérica de regularización tributaria es la prevista en el art. 27 de la LGT y consiste en presentar una autoliquidación o declaración tributaria extemporánea -no precisa ingreso simultáneo-, posee un cierto carácter premial si se realiza antes de que la Administración efectúe requerimiento. El carácter premial deriva de que no se impondrá sanción alguna, si bien existe un gravamen suplementario - de carácter proporcional- al pago de la cuota a ingresar que tiene en cuenta el tiempo demorado en la regularización efectuada. Como puede apreciarse, la regularización tributaria es una figura compleja e híbrida, pues entremezcla consideraciones punitivas con las tributarias.

La denominada amnistía fiscal del RDL 12/2012 es una medida tributaria, pero también punitiva, mediante la cual las personas que habían ocultado bienes pueden regularizar su situación tributaria pagando el $10 \%$ del valor de los no declarados, sin más intereses, recargos, ni multas. Tal institución aúna dos aspectos: la valoración de un cierto arrepentimiento espontáneo ante la conducta ilícita realizada, y la tributación específica que supone. Esta hibridez de contenidos lleva a decir a Alonso González que se trata de un mecanismo de regularización especial ${ }^{6}$.

Sobre tales presupuestos procede analizar, además de su régimen, sus características y naturaleza.

\subsection{El régimen jurídico, una regulación cuestionada}

El estudio de dicha figura requiere contextualizarlo con las diversas modificaciones normativas, coetáneas y posteriores que la significan. Así, no cabe reducir el análisis legal al de la declaración especial que vehicula dicha institución, hay que tener en cuenta las reformas coetáneas efectuadas, en particular la de la LGT, así como las posteriores modificaciones de tal normativa, y su desarrollo a través de una específica orden ministerial.

El Real Decreto-Ley 12/2012, de 30 de marzo, regula en la disposición adicional primera la declaración tributaria especial, e introduce la que popularmente se ha denominado amnistía fiscal. Amnistía, en tanto que supone dejar de perseguir punitivamente un conjunto genérico de conductas. Fiscal, derivado del efecto regularizador y ámbito de aplicación. No obstante, dicha norma es más compleja, pues introduce

\footnotetext{
${ }^{6}$ Alonso L.A., "La declaración tributaria especial: luces y sombras de la 'amnistía fiscal' o el dulce sabor de la zanahoria”, artículo en prensa remitido amablemente por el autor.
} 
dos regímenes temporales de regularización: uno, vinculado estrechamente al impuesto sobre sociedades (en adelante IS) respecto de sociedades radicadas en paraísos fiscales y, otro -objeto de análisis-, respecto de las personas, residentes o no, que a fecha 31 de diciembre de 2010 fueran titulares de bienes o derechos que no se correspondan con las rentas declaradas.

El primero aparece regulado en la Disposición Adicional $15^{\mathrm{a}}$ del LIS (Ley del Impuesto sobre Sociedades) que posibilita repatriar rentas acumuladas en sociedades radicadas en paraísos fiscales a cambio de un "gravamen especial" del $8 \%$. El gravamen se aplica a los dividendos a repartir y a las ganancias derivadas de la transmisión de las participaciones, siempre que la renta se devengue en 2012 y se autoliquide e ingrese en los 25 días siguientes al correspondiente devengo.

El segundo, objeto de comentario, aparece regulado en la Disposición Adicional $1^{a}$ denominándolo "declaración tributaria especial" mediante la que se puede regularizar bienes o derechos que no se correspondan con las rentas declaradas, siempre que se cumplan determinados requisitos formales, temporales, de información, e ingreso. Así, se ha de declarar e ingresar el $10 \%$ de su valor de adquisición antes del 30 de noviembre de 2012, y se ha de facilitar la información necesaria para identificar los bienes de que se trate.

Tales medidas obedecen a dos grandes orientaciones: una principal, de allegar recursos y recaudación y, otra accesoria, de facilitar un mayor control de rentas y bienes situados en el extranjero. Ahora bien, y como señala Falcón y Tella, son normas bastante confusas, "lo que puede disuadir de acogerse a las mismas, especialmente si se anuncian como una medida casi a la desesperada, para paliar el déficit, y no como una alternativa transitoria que se inserta en un calendario preciso de control efectivo de los capitales en el extranjero" 7 .

En tal contexto se ha de tener presente que la OCDE se muestra proclive a combinar medidas de presión a los paraísos fiscales, para que faciliten información, con procedimientos de los propios países para facilitar la regularización de los contribuyentes con elevados patrimonios situados en el extranjero ${ }^{8}$. Ambos son regímenes temporales y extraordinarios en su aplicación, y no modifican, suprimen o sustituyen al tradicional mecanismo de regularización previsto en el art. 27 de la LGT. De ahí que resulten plenamente compatibles, pues obedecen a presupuestos normativos diferentes, normalmente específicos, y temporalmente acotados.

La disposición adicional primera comentada establece la siguiente regulación?:

\footnotetext{
${ }^{7}$ Falcón y Tella, R., "Las fórmulas transitorias de 'regularización' establecidas por el RDL 12/2012, de reducción del déficit: los gravámenes especiales del 8\% y del 10\%”, Quincena Fiscal, núm. 8/2012, consultado en base de datos westlaw.

${ }^{8}$ Falcón y Tella en la obra anteriormente citada alude a los informes de la OCDE de 2008 (The OECD Project on High Net Worth Individuals) y de septiembre de 2010 (Offshore Voluntary Disclosure).

${ }^{9}$ A este respecto, y antes de entrar en vigor tan extraordinaria y urgente medida, el Real Decreto-Ley 19/2012, de 25 de mayo, de medidas urgentes de liberalización del comercio y de determinados servicios en su Disposiciones Final $3^{\mathrm{a}}$ modifica tal regulación añadiendo dos nuevos apartados 6 y 7 . La finalidad es
} 
“1. Los contribuyentes del Impuesto sobre la Renta de las Personas Físicas, Impuesto sobre Sociedades o Impuesto sobre la Renta de no Residentes que sean titulares de bienes o derechos que no se correspondan con las rentas declaradas en dichos impuestos, podrán presentar la declaración prevista en esta disposición con el objeto de regularizar su situación tributaria, siempre que hubieran sido titulares de tales bienes o derechos con anterioridad a la finalización del último período impositivo cuyo plazo de declaración hubiera finalizado antes de la entrada en vigor de esta disposición.

2. Las personas y entidades previstas en el apartado 1 anterior deberán presentar una declaración e ingresar la cuantía resultante de aplicar al importe o valor de adquisición de los bienes o derechos a que se refiere el párrafo anterior, el porcentaje del 10 por ciento.

El cumplimiento de lo dispuesto en el párrafo anterior determinará la no exigibilidad de sanciones, intereses ni recargos.

Junto con esta declaración deberá incorporarse la información necesaria que permita identificar los citados bienes y derechos.

3. El importe declarado por el contribuyente tendrá la consideración de renta declarada a los efectos previstos en el artículo 39 de la Ley 35/2006, de 28 de noviembre, del Impuesto sobre la Renta de las Personas Físicas y de modificación parcial de las leyes de los Impuestos sobre Sociedades, sobre la Renta de no Residentes y sobre el Patrimonio, y en el artículo 134 del texto refundido de la Ley del Impuesto sobre Sociedades, aprobado por el Real Decreto Legislativo $4 / 2004$, de 5 de marzo.

4. No resultará de aplicación lo establecido en esta disposición en relación con los impuestos y períodos impositivos respecto de los cuales la declaración e ingreso se hubiera producido después de que se hubiera notificado por la Administración tributaria la iniciación de procedimientos de comprobación o investigación tendentes a la determinación de las deudas tributarias correspondiente a los mismos.

5. El Ministro de Hacienda y Administraciones Públicas aprobará el modelo de declaración, lugar de presentación e ingreso de la misma, así como cuantas otras medidas sean necesarias para el cumplimiento de esta disposición.

El plazo para la presentación de las declaraciones y su ingreso finalizará el 30 de noviembre de 2012.

6. Cuando el titular jurídico del bien o derecho objeto de la declaración tributaria especial no resida en territorio español y no coincida con el titular real, se podrá considerar titular a este último siempre que llegue a ostentar la titularidad jurídica de los bienes o derechos con anterioridad a 31 de diciembre de 2013.

7. El valor de adquisición de los bienes y derechos objeto de la declaración especial será válido a efectos fiscales en relación con los impuestos a que se refiere el apartado 1

determinar el valor a efectos fiscales de los bienes o derechos que hayan sido objeto de declaración e introducir ciertas cautelas para evitar situaciones de desimposición. 
anterior, a partir de la fecha de presentación de la declaración y realización del ingreso correspondiente. No obstante, cuando el valor de adquisición sea superior al valor normal de mercado de los bienes o derechos en esa fecha, a efectos de futuras transmisiones únicamente serán computables las pérdidas o en su caso, los rendimientos negativos, en la medida que excedan de la diferencia entre ambos valores.

En ningún caso serán fiscalmente deducibles las pérdidas por deterioro o correcciones de valor correspondientes a los bienes y derechos objeto de la declaración especial, ni las pérdidas derivadas de la transmisión de tales bienes y derechos cuando el adquirente sea una persona o entidad vinculada en los términos establecidos en el artículo 16 del texto refundido de la ley del Impuesto sobre Sociedades, aprobado por el Real Decreto Legislativo 4/2004, de 5 de marzo.

Cuando sean objeto de declaración bienes o derechos cuya titularidad se corresponda parcialmente con rentas declaradas, los citados bienes o derechos mantendrán a efectos fiscales el valor que tuvieran con anterioridad a la presentación de la declaración especial".

A los efectos de completar las previsiones respecto de la declaración especial se dicta la orden HAP/1182/2012, de 31 de mayo, por la que se desarrolla la Disposición Adicional primera del Real Decreto-Ley 12/2012, de 30 de marzo, por el que se introducen diversas medidas tributarias y administrativas dirigidas a la reducción del déficit público, se aprueban cuantas medidas resultan necesarias para su cumplimiento, así como el modelo 750, declaración tributaria especial, y se regulan las condiciones generales y procedimiento para su presentación. Dicha disposición contiene el modelo de presentación de la declaración tributaria especial, la forma en que se ha de presentar, y algunas disposiciones para su aplicación. También se ha emitido un Informe de la Dirección General de Tributos (DGT) el día 27 de junio, sobre diversas cuestiones relativas al procedimiento de regularización derivado de la presentación de la declaración tributaria especial que trata no pocos aspectos sustanciales de dicha regularización ${ }^{10}$.

El Real Decreto-Ley 12/2012 ha resultado objeto de fuerte polémica social y política, de manera que en la actualidad está impugnado mediante un recurso de inconstitucionalidad ante el Tribunal Constitucional (en adelante TC) de fecha de 15 de junio de 2012 por los parlamentarios del grupo socialista. También se ha interpuesto un recurso contencioso administrativo ante la Audiencia Nacional contra la orden ministerial HAP/1182/2012 que desarrolla dicha medida. Nótese que dicha impugnación genera una peculiar problemática en caso de que se declare inconstitucional, por vicios de legalidad o por vulnerar principios constitucionales como el de igualdad, pues no existiría regularización y podrían imponerse las sanciones que tal medida enerva.

Atendiendo a las medias normativas coetáneas, el Real Decreto-Ley 12/2012 también modifica algunas disposiciones de la Ley 58/2003, de 17 de diciembre, General

${ }^{10}$ Alonso L.A., "La declaración tributaria especial: luces y sombras de la 'amnistía fiscal' o el dulce sabor de la zanahoria", artículo en prensa remitido amablemente por el autor. 
Tributaria, con especial incidencia en la amnistía comentada. Así, el art. 180.2 de la LGT establece en caso de regularización la exoneración "de su responsabilidad penal, aunque la infracción en su día cometida pudiera ser constitutiva de delito contra la Hacienda Pública”. La literalidad de tales menciones entraña no pocas dudas sobre si se declara una exención de toda responsabilidad penal (incluyendo delitos como el de blanqueo), no tan solo la exigible en vía administrativa.

De manera análoga a las anteriores orientaciones se tramita en la actualidad el Proyecto de Ley de modificación de la normativa tributaria y presupuestaria y de adecuación de la normativa financiera para la intensificación de las actuaciones en la prevención y lucha contra el fraude ${ }^{11}$. Dicho proyecto fue informado en el Consejo de Ministros el 13 de abril de 2012, y pretende reforzar las actuaciones de prevención contra el fraude fiscal. Se presenta como un complemento perfecto al plan extraordinario de regularización de rentas ocultas aprobado el 30 de marzo de 2012, por el que se pretende la afloración de ingresos procedentes de la economía sumergida y su incorporación a la economía regular antes del 30 de noviembre de 2012 .

Teniendo presente tal contexto normativo cabe analizar las características de la medida establecida para, posteriormente, tratar su naturaleza.

\subsection{Las características del gravamen y de la regularización}

La medida establecida prevé unas consecuencias premiales de exoneración y condonación, vinculadas a la realización de una concreta declaración tributaria y al pago del $10 \%$ del valor de adquisición de los bienes. Tanto el gravamen establecido como el efecto regularizador que comporta presentan notas singulares.

El gravamen específico del 10\% del valor de adquisición de los bienes se caracteriza por ${ }^{12}$ :

a) Ser un gravamen directo, personal, objetivo y de carácter proporcional que afecta a concretos impuestos. En tal orientación, los impugnantes de inconstitucionalidad

${ }^{11}$ En el momento de revisar estas páginas ya se publica como Ley 7/2012, de 29 de octubre. La aparición y tramitación de esta Ley $7 / 2012$, de prevención y lucha contra el fraude, posee una cierta nota conminatoria a la regularización fiscal prevista en el Real Decreto Ley 12/2012. Dicha norma, por el momento de su tramitación y su contenido, pretende incentivar la regularización extraordinaria que supone la amnistía fiscal. Así se deduce de relacionar dos aspectos, uno vinculado al momento de su tramitación y, el otro, relativo a las medidas que prevé. Por un lado, la ley se ha tramitado mediante un procedimiento de urgencia -conforme a los artículos 148 y 93 del Reglamento del Congreso-durante la vigencia del plazo para ejercitar la amnistía fiscal. Por otro lado, incide en el ámbito de la amnistía fiscal la obligación específica de información -reforzada con sanción tributaria- en materia de bienes y derechos situados en el extranjero. También los efectos tributarios y sancionadores establecidos respecto de las ganancias de patrimonio no justificadas del IRPF y de la presunción de obtención de rentas en el IS.

${ }^{12}$ Ver análisis de Aneiros, J., "La amnistía fiscal de 2012 y otras medidas que pretenden atraer capitales españoles en el exterior”, Ferrer Pedrola, R., "Notas preliminares a la regulación fiscal de 2012: Comentarios de urgencia”, y Martin Fernández, J.: "Comentarios al Real Decreto-Ley 12/2012, de 30 de marzo, por el que se introducen diversas medidas tributarias y administrativas dirigidas a la reducción del déficit público”, en web de la Asociación Española de Asesores Fiscales 2012. 
de tal medida afirman que el contenido de esta norma revela la estructura de un nuevo gravamen, de carácter temporal, naturaleza personal y directa, de sujeción voluntaria y, lo que resulta más llamativo, alternativo al Impuesto sobre la Renta de las Personas Físicas (IRPF), al Impuesto sobre Sociedades (IS) y al Impuesto sobre la Renta de no Residentes (IRNR). Estos tres impuestos son pilares básicos o estructurales de nuestro sistema tributario, por lo que esta nueva figura -continúan dichos impugnantes- no puede ser establecida mediante un decreto ley. Por tanto, concluyen, que el Real Decreto-Ley 12/2012 provoca un cambio sustancial en la posición de los ciudadanos en el conjunto del sistema tributario, lo que desde esta perspectiva es claramente inconstitucional ${ }^{13}$.

b) El objeto de gravamen es un patrimonio oculto integrado por bienes o derechos. No se grava renta, a pesar de ubicarse en impuestos (IRPF, IS, IRNR) cuyo fin principal es dicho gravamen. Se grava la titularidad de un patrimonio, sobre la base de que tuvo su origen en una renta no declarada.

c) El incentivo que se asocia a dicho gravamen es la exención de la responsabilidad sancionadora tributaria, y la condonación de la deuda tributaria que pudiera corresponder respecto de los anteriores periodos impositivos ${ }^{14}$.

d) Es un gravamen excepcional, por su previsión legal inusual, por el carácter opcional que supone para el obligado, y por la temporalidad de su ejercicio. Si no se ejercita en el plazo que se prevé, caduca.

La declaración y el abono en tiempo y forma del anterior gravamen origina una regularización tributaria y punitiva caracterizada -en orden a sus consecuencias- por ser:

$1^{\circ}$. Una regularización parcial, de algunos impuestos. De su ámbito de aplicación se observa que únicamente opera respecto de los contribuyentes del IRPF, IS e IRNR, excluyendo a otros impuestos que pudieran concurrir. En el caso de haberse devengado impuestos no acogidos en el ámbito de tal regulación se habrán de regularizar según las disposiciones generales ordinarias, básicamente, atendiendo a lo que señala el art. 27 de la LGT.

${ }^{13}$ Señala Alonso González que " $[. .$.$] no se puede negar que suscita serias dudas que sea un Decreto Ley$ la norma adecuada para alumbrar, ni más ni menos, que un gravamen, digamos, de naturaleza tributaria. Precisamente, la escurridiza naturaleza jurídica que se quiere adjudicar a la DTE (declaración tributaria especial) en las normas que lo regulan, y también por parte de la DGT, puede responder, en el fondo, al menos en parte, a intentar evitar que se pueda afirmar sonoramente que se ha aprobado un tributo por un Decreto-Ley, algo, a todas luces, inconstitucional (art. 86 CE)" (Alonso L.A., "La declaración tributaria especial: luces y sombras de la 'amnistía fiscal' o el dulce sabor de la zanahoria”, artículo en prensa remitido amablemente por el autor).

${ }^{14} \mathrm{~A}$ este respecto se ha de tener presente que la orden ministerial permite la regularización de bienes que aparezcan a nombre de un testaferro, o sea, el sujeto que posee el control de los bienes y derechos mediante personas o entidades que los administran o mediante instrumentos jurídicos que los controlan. 
$2^{\circ}$. Una regularización temporal. Dicho aspecto se vertebra en dos consideraciones: el momento de regularización y los bienes que pueden ser regularizados. La declaración especial se puede presentar hasta el 30 de noviembre de 2012.

Los bienes y derechos a regularizar han de ser anteriores al 31 de diciembre de $2010^{15}$. Ahora bien, el criterio temporal de los bienes a regularizar se excepciona en el caso del dinero en efectivo, ya que permite que se declare (confiando sorprendentemente en la palabra del obligado) que se poseían con anterioridad al 31 de diciembre de 2012. Tal situación plantea un problema de legalidad, debido a que dicha previsión aparece en la orden ministerial y no se contiene expresamente en el Decreto-Ley y, desde un punto de vista material, no se garantiza suficientemente que el dinero sea anterior al 31 de diciembre de $2010^{16}$. Se origina así una posible innovación ilícita a través de una orden ministerial, pues la condonación de la deuda exige ley según la LGT.

$3^{\circ}$.Una regularización específica, que la diferencia de la ordinaria del art. 27 de la LGT, por su carácter temporal y por exigir ingreso. Formalmente se ha de efectuar mediante una declaración en la que se identifiquen los bienes, pero además y como requisito intrínseco de operatividad, se exige su ingreso. No obstante, se asemeja a la regularización del art. 27 de la LGT en que en ningún caso puede existir un procedimiento tributario abierto de exigencia, o información, sobre los activos a regularizar. La amnistía fiscal no excluye la aplicación de la regularización ordinaria. Puede resultar una opción tributaria lícita el acogerse a la regularización del art. 27 de la LGT cuando la renta a pagar sea inferior al $10 \%$ que supone tal gravamen.

$4^{\circ}$.Una medida extraordinaria, aunque no inédita, pues en el pasado reciente han existido otras regularizaciones similares, como las establecidas mediante la Ley 50/1977, de 14 de noviembre, la Ley 14/1985, de 29 de mayo y la Ley 18/1991, de 6 de junio ${ }^{17}$.

${ }^{15}$ Dicha fecha se determina por la publicación del Real Decreto que contenía la medida, en la idea de que sean ejercicios fiscales vencidos, y las nuevas bases imponibles se incorporen en las ya controladas por la Administración. Así, se exige haber sido titular de bienes o derechos con anterioridad al último período impositivo cuyo plazo de declaración hubiera finalizado antes de la entrada en vigor de esta disposición.

${ }^{16}$ En el artículo 3.4 de la orden ministerial se dan las pautas para la regularización del efectivo: “( ), tratándose de dinero en efectivo será suficiente la manifestación, a través del modelo de declaración, de ser titular del mismo con anterioridad a 31 de diciembre de 2010, o a la fecha de finalización del periodo impositivo a que se refiere el apartado 2 anterior, siempre que con carácter previo a la presentación de la declaración tributaria especial se hubiera depositado en una cuenta cuya titularidad jurídica corresponda al declarante abierta en una entidad de crédito residente en España, en otro Estado de la Unión Europea, o en un Estado integrante del Espacio Económico Europeo que haya suscrito un convenio con España para evitar la doble imposición internacional con cláusula de intercambio de información o un acuerdo de intercambio de información en materia tributaria, y no se trate de jurisdicciones calificadas como de alto riesgo, deficientes o no cooperativas por el Grupo de Acción Financiera Internacional”.

${ }^{17}$ La Ley 50/1977 permitía una regularización voluntaria de la situación fiscal mediante la presentación de declaraciones complementarias. Es una amnistía preconstitucional que renunciaba a imponer sanciones y recargos, efectuando un tratamiento más favorable a las personas jurídicas al eximirles también del pago de cuotas. Es una medida que históricamente cumplía la función de obtener información tributaria para implantar el futuro modelo de tributación. Con la Ley 14/1985 se permitía a los titulares de rentas ocultas 


\subsection{La problemática de su naturaleza bíbrida}

Dicha regularización pretende incrementar los ingresos públicos en un momento crítico, en donde resulta necesario allegar fondos para cumplir con los criterios de estabilidad presupuestaria y reducción del déficit ${ }^{18}$. Se plantea así como una medida extrafiscal vinculada a la crisis económica. Con ella se busca que afloren bienes y derechos no declarados por los obligados, en definitiva, ocultados - la Disposición Adicional $1^{\circ}$ habla eufemísticamente de bienes o derechos que no se correspondan con la renta declarada-. Son bienes o derechos ubicados normalmente en paraísos fiscales, lugares en donde -al margen de una mejor tributación- resultan opacos a la Administración.

Pero también posee una finalidad estrictamente fiscal, pues existe una tributación, aunque menor a la ordinaria, y permite mejorar el control futuro de los bienes declarados.

Para el análisis de la naturaleza de la medida cabe tener presente dos perspectivas: una formal, que contemple la declaración tributaria a través de la que se efectúa dicha regularización, y otra material, que analice el importe a abonar. Ambas ponen de relieve la singularidad que supone dicha regulación.

Desde la perspectiva formal, como instrumento de regularización se utiliza lo que se denomina declaración tributaria especial. Su singularidad radica en el hecho de que no tienen como finalidad practicar una liquidación tributaria, ni se corresponde con una obligación devengada con anterioridad. La declaración presentada no es, en sentido estricto o pleno, una autoliquidación ${ }^{19}$. De ahí que la previsión de tal especialidad en una norma reglamentaria, y no legal, resulte cuanto menos perturbadora e inadecuada.

Desde la perspectiva material del gravamen a pagar, no se trata de un impuesto especial, pues no determina un hecho imponible, ni los demás elementos constitutivos de un impuesto propio y autónomo. Se relaciona con impuestos ya existentes, y con concretas calificaciones jurídicas del IRPF, IS o IRNR.

\footnotetext{
adquirir deuda pública (pagarés del Tesoro Público) a cambio de no exigir impuestos, recargos o sanciones y salvaguardando el anonimato de los titulares. En las Disposiciones adicionales $13^{\mathrm{a}}$ y $14^{\mathrm{a}}$ de la Ley 18/1991, de 6 de junio, del Impuesto sobre la Renta de las Personas Físicas, se preveían medidas de canje de activos financieros y regularización de situaciones tributarias con el fin de aflorar rentas no declaradas invertidas en títulos emitidos por territorios forales.

${ }^{18}$ Así, la Exposición de Motivos del Decreto Ley 12/2012 afirma que "También con el fin de reducir el déficit público, se establece una declaración tributaria especial para determinadas rentas y se adoptan medidas de carácter administrativo que contribuyan a generar ahorros en la gestión del patrimonio inmobiliario del sector público".

${ }^{19}$ Así lo apunta la Exposición de Motivos de la Orden Ministerial cuando señala que "La configuración jurídica de la declaración tributaria especial integra elementos propios de las autoliquidaciones tributarias, sin que pueda predicarse de la misma un ajuste total, en lo que a sus elementos constitutivos se refiere, a la regulación que de las mismas se contiene en la Ley 58/2003, de 17 de diciembre, General Tributaria, no siendo sus efectos jurídicos, por la misma razón, análogos a los que con carácter general se derivan de estas últimas”. En el art. 1 de la Orden se afirma que la declaración especial participa de la naturaleza de las autoliquidaciones y constituye una declaración tributaria, pero sorprendentemente su presentación no tiene como finalidad "la práctica de una liquidación tributaria".
} 
Se considera el patrimonio así declarado como ganancias no justificadas, según se deduce de la remisión -apartado 3- al art. 39 de la LIRPF y al art. 134 de la LIS. Ahora bien, con tal medida no se pretende gravar la capacidad contributiva propia de los tributos que señala, pues se establece un único porcentaje -el 10\%-que no resulta de los tipos aplicables genéricamente al IRPF, IS o IRNR ${ }^{20}$. En todo caso, resulta un tipo reducido o bonificado en los términos del art. 55.3 de la LGT.

La regularización se reduce a los bienes que pudieran considerarse normativamente como ganancia no justificada, no admitiéndose otra calificación. En tal orientación parece posicionarse el criterio n ${ }^{\circ} 6$ del Informe de la Dirección General de Tributos al afirmar que "la presentación de la declaración tributaria especial determina que la adquisición de los bienes o derechos regularizados que se habían mantenido ocultos se entienda que corresponde con rentas declaradas (el importe declarado) y por tanto no pueden tener la consideración de ganancias patrimoniales no justificadas o como renta presunta en ese mismo ejercicio o en ejercicios posteriores”. También Falcón y Tella efectúa una interpretación estricta de dicha regularización para salvar su inconstitucionalidad, pues la vincula únicamente en relación con los arts. 39 de la Ley del IRPF o 134 de la LIS no abarcando otros efectos. Así, si los activos ocultos han dado lugar a ingresos por intereses, alquileres, dividendos, o ganancias de patrimonio, tales rentas deberán ser objeto de una declaración complementaria con los recargos del art. 27 LGT $^{21}$.

Atendiendo a tal operatividad dicha regularización se asemeja a un recargo extemporáneo y voluntario, debido a que actúa antes de que la Administración notifique el inicio de un procedimiento de comprobación o investigación (apartado 4). También lo apunta el hecho de que excluya la aplicación de sanciones (apartado 2). Así, para que se aplique dicha norma es necesario el arrepentimiento propio de la regularización -comunicar espontáneamente antes de que se inicie actuación administrativa-, y el ingreso de la totalidad de la deuda. Se aúnan así dos aspectos: la valoración del arrepentimiento en el sujeto y su colaboración en la recaudación. Este último carácter -el ingreso- parte del supuesto de que todos los sujetos son solventes, y si no pagan es porque voluntariamente no lo desean. Pero, ¿qué sucede con las personas que carecen de recursos? No podrán aplicar dicha medida y tendrán que acogerse a la regularización genérica del art. 27 de la LGT. Tal aspecto remarca la vinculación de dicha regularización con la recaudación, deviniendo esta un aspecto esencial.

La amnistía comentada se asemeja prima facie a un recargo específico, equivalente al recargo ordinario en su tramo de tres meses y un día a los seis meses, con la necesidad de ingreso. No obstante, se diferencia drásticamente de dicho recargo al existir cuota tributaria previa, ya que se aplica sobre el importe o valor de adquisición. Por

${ }^{20}$ De ahí que Alonso González afirme que se trata de un tributo nuevo, de carácter temporal, extraordinario, y alternativo al IRPF/IRNR/IS que sirve para regularizar determinadas rentas no declaradas sujetas a esos impuestos (Alonso L.A., "La declaración tributaria especial: luces y sombras de la 'amnistía fiscal' o el dulce sabor de la zanahoria", artículo en prensa remitido amablemente por el autor).

${ }^{21}$ Falcón y Tella, R., "Las fórmulas transitorias de 'regularización’ establecidas por el RDL 12/2012, de reducción del déficit: los gravámenes especiales del $8 \%$ y del 10\%”. Op. cit. 
consiguiente, en ningún caso podrá hablarse de recargo al no ser una cuantía accesoria de la cuota previa.

Ahora bien, origina una eficacia específica respecto de las deudas pasadas, ya que supone una cierta condonación de las mismas. Es una medida que flexiona la normaprincipio relativa a la indisponibilidad del crédito tributario, de manera particular, respecto de la posición acreedora, ya que no puede conceder moratorias ni perdones, salvo que la ley establezca otra cosa (art. 18 de la LGT).

En puridad nos encontramos ante una medida híbrida: en el plano punitivo, se origina una condición negativa de procedibilidad ${ }^{22}$; en el plano tributario, una aparente condonación parcial (se deja de pagar la -generalmente- mayor cuantía debida).

Punitivamente se trata de un supuesto que enerva la actuación administrativa en la indagación de la responsabilidad sancionadora concurrente. Resulta un requisito de procedibilidad negativo. De procedibilidad, en tanto que tiene que ver con el inicio del procedimiento sancionador. No se puede afirmar que enerve sanción alguna, pues no se ha iniciado el procedimiento de indagación oportuno. El carácter negativo afirmado aparece asociado al hecho de que su concurrencia evita el inicio de dicho procedimiento, y la indagación de los elementos constitutivos de la infracción. Así, no se enerva la punición de infracción alguna, pues esta no se halla determinada en ninguno de sus elementos ${ }^{23}$.

Tampoco se trataría, en sentido estricto, de una condonación tributaria al no existir deuda previa la cual perdonar. No origina tampoco una novación, pues esta exige una deuda previa que no resulta determinada. Dicha medida rezuma un efecto sustitutorio de las eventuales obligaciones tributarias pasadas no liquidadas, si bien no exige constatar su existencia ni cuantía. En tal regulación existe un componente propio del olvido, consustancial a la amnistía, que se asocia a un aspecto sustitutivo-pago del $10 \%$ - de una probable deuda pasada superior. A diferencia del ámbito punitivo, donde la regularización enerva la posibilidad de indagar la responsabilidad de tal naturaleza, en el tributario manifiesta un carácter sustitutivo de las anteriores eventuales obligaciones con el abono del $10 \%$ del valor de adquisición señalado.

En definitiva, se trata de un gravamen específico inserto en la tributación general de determinados impuestos con efectos regularizadores, pues su gravamen al $10 \%$ exime de cualquier sanción y pago de cuota. En el mismo se evalúa más que la capacidad económica la inmediata recaudación que origina.

${ }^{22}$ Falcón y Tella señala que con tal medida no se perdonan delitos o infracciones, no se trata de una amnistía en sentido estricto, se trata de una excusa absolutoria específica paralela a la ya existente en el art. 27 LGT (Falcón y Tella, R., "Las fórmulas transitorias de 'regularización’ establecidas por el RDL 12/2012, de reducción del déficit: los gravámenes especiales del $8 \%$ y del 10\%”. Op. cit.).

23 En tal sentido nos posicionábamos en Sánchez, M.A., Las infracciones tributarias en la nueva $L G T$, Marcial Pons, Madrid, 2008. 


\section{LOS EFECTOS DE LA REGULARIZACIÓN}

La amnistía aprobada posee consecuencias en dos órdenes normativos diversos, en el fiscal y en el punitivo.

En el plano fiscal genera tres efectos. Uno que mira al pasado, y supone la no exigencia de la eventual deuda tributaria no prescrita. Otro que contempla el presente, y que supone el declarar e ingresar en plazo y forma los bienes y derechos sujetos al gravamen. Y el último se orienta al futuro, en tanto que conlleva una información tributaria relevante -posibilita un control de tales bienes-y origina un pronóstico favorable sobre el gravamen futuro. Esta última eficacia entra de lleno en consideraciones más de política tributaria que estrictamente jurídicas.

En el plano punitivo a quienes realicen dicha regularización, se les eximirá de su responsabilidad respecto de las sanciones tributarias que pudieran corresponderles. Dicha eficacia se extiende, según el art. 180.2 de la LGT, a la exoneración de su responsabilidad penal. La literalidad de tales menciones entraña no pocas dudas sobre si se declara la ausencia de toda responsabilidad penal, sea cual sea el delito cometido.

Las anteriores consecuencias generales contextualizan problemáticas específicas y algunos efectos paradójicos. En concreto, cabe poner de relieve las implicaciones punitivas respecto del delito de blanqueo de capitales, y las tributarias relativas a si se lesiona el principio de igualdad con la discrepancia de trato originada.

\subsection{El blanqueo de capitales: las otras implicaciones punitivas}

La regularización se ve incentivada por la baja tributación que resulta y por la inexistencia de infracción tributaria, pues supone una condición de procedibilidad que impide iniciar el procedimiento sancionador administrativo para declarar la responsabilidad. Dicha eficacia se extiende, según el art. 180.2 de la LGT modificado por el Real Decreto-Ley 12/2012, a la exoneración "de su responsabilidad penal, aunque la infracción en su día cometida pudiera ser constitutiva de delito contra la Hacienda Pública”. Tal mención entraña dudas sobre si establece una exención de toda responsabilidad penal, incluida la que podría originarse por un delito por blanqueo de los bienes que tributariamente se regularizan.

El art. 180.2 de la LGT alude a regularizaciones generales, de toda deuda tributaria, y permanentes, ya sea de las practicadas con el carácter extraordinario, propio de tal disposición adicional primera, como las previstas en el art. 27 de la LGT. Ahora bien, posee una implicación específica respecto de la amnistía comentada al exigirse, en ambos casos, una regularización con ingreso de la deuda. Así, exime de responsabilidad penal a las regularizaciones fiscales realizadas antes de notificado el inicio de actuaciones administrativas, si existe ingreso de la deuda.

La dicción de tal precepto genera interrogantes sobre la extensión de las consecuencias que señala al exonerar de responsabilidad penal. Surge la duda sobre si tal regularización tributaria origina la impunidad del eventual delito de blanqueo cometido. Dilucidar tal cuestión pasa por tener presente tres consideraciones. 
En primer lugar, no puede afirmarse una ausencia de la responsabilidad penal sin haber iniciado el procedimiento punitivo de indagación. Es por ello que tal mención resulta, más que una exención, una condición negativa de procedibilidad que impide el inicio de la averiguación de dicha responsabilidad.

En segundo lugar, una ley ordinaria no puede modificar las previsiones de una ley orgánica, que es la encargada de regular los delitos y las penas a imponer por la jurisdicción. La Ley General Tributaria, al poseer rango de ley ordinaria, no podrá modificar las previsiones del Código penal (en adelante también $\mathrm{Cp}$ ) con rango orgánico.

La genérica exención de responsabilidad penal afirmada por la ley se ha de reinterpretar para salvar su inconstitucionalidad, al poder afectar al principio de jerarquía normativa -art. 9.3 de la CE-. Así, se ha de entender que la expresión "penal" hace referencia al ámbito sancionador de la Administración, y no al propio de la intervención de la jurisdicción y de la aplicación del Código penal. Entenderlo de otra forma originaría una amnistía delictiva genérica y encubierta que legitimaría la posesión de bienes de procedencia ilícita.

En tercer lugar, la eventual exoneración de responsabilidad respecto del delito contra la Hacienda Pública podrá resultar válida en la medida que se adecue a las previsiones del art. 305.4 del Cp. Intentar reiterar la exención penal parece ser la intención de la reforma, a decir de la Exposición de Motivos $^{24}$. Ahora bien, la viabilidad o no de tal exención corresponde apreciarla a la autoridad judicial, y no a la administrativa. La decisión administrativa en ningún caso puede condicionar y vincular a la jurisdicción.

La lógica y efectos de tal precepto, a nuestro entender, se sitúa en el ámbito administrativo y en el seno del procedimiento tributario. De otra forma, podría ser considerado inconstitucional, pues no puede, debido a su rango legal, determinar la exoneración de la responsabilidad penal, ni predeterminar la decisión del juez. La finalidad de la disposición es afirmar la continuación de la tramitación del procedimiento tributario, independientemente de que se abra un procedimiento jurisdiccional de carácter penal, como se deduce cuando afirma que “[...] la Administración podrá continuar con el procedimiento administrativo sin pasar el tanto de culpa a la autoridad judicial ni al Ministerio Fiscal [...]" (art. 180.2 de la LGT).

Dentro de las consecuencias penales de la amnistía fiscal resulta de interés analizar su eficacia en relación con el delito y la legislación de prevención de blanqueo de bienes.

El blanqueo de capitales constituye un delito que consiste en ocultar y legitimar el origen de fondos procedentes de actuaciones ilícitas. Las actividades que habitualmente generan bienes ilícitos son comportamientos delictivos como el narcotráfico, prostitución, tráfico ilegal de drogas, de armas... El aspecto esencial de la conducta de blanqueo es

${ }^{24}$ La misma afirma que "se considera importante favorecer que los obligados tributarios puedan ponerse voluntariamente al corriente de sus obligaciones tributarias regularizando también situaciones pasadas, siguiendo en esta línea la norma penal que admite la exoneración de responsabilidad penal por estas regularizaciones voluntarias efectuadas antes del inicio de actuaciones de comprobación o, en su caso, antes de la interposición de denuncia o querella. A tal efecto se introduce la correspondiente modificación en la Ley General Tributaria". 
la realización de cualquier acto para ocultar o encubrir el origen ilícito de los bienes, o para ayudar a las personas que hayan participado en la infracción ${ }^{25}$.

La eficacia de la amnistía fiscal, en relación con el blanqueo y las normas que lo previenen, hay que analizarla teniendo presente los diversos sujetos a que atañe dicha conducta: el obligado tributario, el profesional que le asesora, y la Administración interviniente.

Si el obligado tributario ha realizado el delito de blanqueo, la regularización tributaria no le eximirá de su responsabilidad penal. La previsión del art. 180.2 de la LGT, reiteramos, carece del rango normativo suficiente para ello.

Respecto del profesional que ha intervenido asesorando al obligado con anterioridad a la regularización, decir que la regularización de su cliente no le exime de los deberes de denuncia que tenía establecidos por la Ley 10/2010, de 28 de abril, de Prevención del Blanqueo de Capitales y de Financiación del Terrorismo. La regulación tributaria analizada no establece exención específica y expresa del deber de denuncia y diligencia profesional que afirma la citada ley de prevención.

La Ley 10/2010 impone a los profesionales que ejercen asesoramiento fiscal una serie de obligaciones cuya finalidad es prevenir las conductas de blanqueo, así se deduce del art. 2.1 en su apartado ñ) al referirse a los abogados y a los otros profesionales que realicen operaciones societarias o de gestión de fondos ${ }^{26}$. Dicha norma también destaca concretas operaciones sobre las que corresponde informar, por ejemplo, en caso de pagos o movimientos por importe superior a $10.000 €$ (art. 34) o los supuestos del art. 38. Por su especial relevancia tributaria cabe destacar las obligaciones de análisis, de constancia por escrito, y de comunicación de las operaciones sin un propósito económico o lícito aparente o que presenten indicios de simulación o fraude ${ }^{27}$.

De lo anterior resulta que la regularización tributaria del cliente puede poner en evidencia el incumplimiento por parte del profesional de la normativa de blanqueo de

${ }^{25}$ Ver en tal sentido las diversas posturas en Aranguez Sánchez, C., El delito de blanqueo de capitales,. Marcial Pons, Madrid, 2000, pp. 77-107, Blanco Cordero, I., El delito de blanqueo de capitales. Aranzadi. Pamplona. 2002, pp. 177-233, Muñoz Conde, F., Derecho Penal. Parte especial, Tirant lo Blanch, Valencia, 2007, pp. 537, Córdoba Roda, J. y García Aran, M., Comentarios al Código Penal. Parte especial, Tomo I, Marcial Pons, Madrid, 2004, pp. 1151-1152.

${ }^{26}$ A este respecto ver Aneiros Pereira, J., "Las obligaciones de prevención del blanqueo de capitales a cargo de determinados profesionales: una fuente de información tributaria”, Revista Técnica Tributaria, $\mathrm{n}^{\circ} 91$. 2011, también "Las implicaciones de la normativa de prevención del blanqueo de capitales para los asesores fiscales". Documentos de la AEDAF. 2011.

27 Señala el art. 17. 1:"Los sujetos obligados examinarán con especial atención cualquier hecho u operación, con independencia de su cuantía, que, por su naturaleza, pueda estar relacionado con el blanqueo de capitales o la financiación del terrorismo, reseñando por escrito los resultados del examen. En particular, los sujetos obligados examinarán con especial atención toda operación o pauta de comportamiento compleja, inusual o sin un propósito económico o lícito aparente, o que presente indicios de simulación o fraude”. El art. 18 "1. Los sujetos obligados comunicarán, por iniciativa propia, al Servicio Ejecutivo de la Comisión de Prevención del Blanqueo de Capitales e Infracciones Monetarias (en adelante, el Servicio Ejecutivo de la Comisión) cualquier hecho u operación, incluso la mera tentativa, respecto del que, tras el examen especial a que se refiere el artículo precedente, exista indicio o certeza de que está relacionado con el blanqueo de capitales o la financiación del terrorismo [ ]”. 
capitales. Se ha de tener presente que la exigencia de tal responsabilidad administrativa de prevención del blanqueo no se vincula a la constatación de un delito de blanqueo a cargo del cliente. Se trata de un deber de carácter preventivo que no precisa constatar el resultado lesivo de la conducta que debe comunicar. Por consiguiente, la condición negativa de procedibilidad para la sanción tributaria que se establece para el obligado en la amnistía fiscal no alcanza a la posible sanción a imponer al profesional.

La regularización efectuada pondría en evidencia la comisión de una eventual infracción del profesional, que la Administración tributaria tendría que poner en conocimiento de la administración de prevención del blanqueo de capitales. Así se establece en el deber informativo genérico del art. 48.1 de la Ley 10/2010 para toda autoridad o funcionario en caso de que "descubra hechos que puedan constituir indicio o prueba de blanqueo de capitales o de financiación del terrorismo, ya sea durante las inspecciones efectuadas a las entidades objeto de supervisión, o de cualquier otro modo". La administración tributaria, concretamente las autoridades o funcionarios que conozcan de tales hechos, serán responsables ante el incumplimiento de tal deber de colaboración informativa.

\subsection{Discordancia con el principio de igualdad}

En caso de existir un agravio comparativo sin suficiente justificación la amnistía tributaria comentada puede originar una quiebra al principio de igualdad. El agravio comparativo derivaría de la diversa y más favorable tributación a la que se acogen aquellas personas que regularizan con la amnistía fiscal. Su justificación es básicamente extrafiscal: las necesidades de recaudación. Tal aspecto no parece fundamentar el diverso trato originado y, en menor medida, cuando tiene como antecedente una conducta con claros indicios de ser reprobable punitivamente.

La Constitución española garantiza la igualdad ante la ley, o sea, que el tratamiento efectuado no genere discriminación entre la ciudadanía. El principio de igualdad conlleva dos afirmaciones: el tratamiento igualitario de situaciones e individuos en idénticas circunstancias, y el tratamiento acorde a su desigualdad de situaciones o circunstancias disímiles. En tal sentido existe una amplia jurisprudencia de donde se deriva la prohibición de las desigualdades arbitrarias o carentes de justificación. En la delimitación de tales extremos los juicios de proporcionalidad resultan de gran relevancia ${ }^{28}$.

${ }^{28}$ Síntesis de la doctrina sobre el principio de igualdad ante la ley resulta la Sentencia del Tribunal Constitucional 76/1990, de 26 de abril [RTC 1990, 76], y establece: a) no toda desigualdad de trato en la ley supone una infracción del art. 14 de la Constitución, sino que dicha infracción la produce solo aquella desigualdad que introduce una diferencia entre situaciones que pueden considerarse iguales y que carece de una justificación objetiva y razonable; b) el principio de igualdad exige que a iguales supuestos de hecho se apliquen iguales consecuencias jurídicas, debiendo considerarse iguales dos supuestos de hecho cuando la utilización o introducción de elementos diferenciadores sea arbitraria o carezca de fundamento racional; c) el principio de igualdad no prohíbe al legislador cualquier desigualdad de trato, sino solo aquellas desigualdades que resulten artificiosas, o injustificadas por no venir fundadas en criterios objetivos y suficientemente razonables de acuerdo con criterios o juicios de valor generalmente aceptados; d) por último, para que la diferenciación resulte constitucionalmente lícita no basta con que lo sea el fin que con ella se persigue, sino que es indispensable además que las consecuencias jurídicas que resultan de tal distinción sean adecuadas y 
Así, las diferencias normativas son conformes con la igualdad cuando cabe discernir en ellas una finalidad no contradictoria con la Constitución y cuando, además, las normas muestran una estructura coherente, en términos de razonable proporcionalidad, con el fin así perseguido. Tan contraria a la igualdad es, por lo tanto, la norma que diversifica por un mero voluntarismo selectivo como aquella otra que, atendiendo a la consecución de un fin legítimo, configura un supuesto de hecho, o las consecuencias jurídicas que se le imputan, en desproporción patente con aquel fin o sin atención alguna a esa necesaria relación de proporcionalidad (Sentencias del Tribunal Constitucional 75/1983 [ RTC 1983, 75], de 3 de agosto, y 96/2002 [ RTC 2002, 96], de 25 de abril).

La normativa sobre la regularización extraordinaria objeto de análisis confronta dos situaciones diversas: en una, los sujetos no han tributado por sus bienes y derechos y, en otra, los sujetos que sí lo han efectuado. A los sujetos que no tributaron se les grava con el 10\%, mientras que a los sujetos cumplidores se les aplica la legislación ordinaria vigente. Dicho planteamiento, trasladado al ejemplo numérico propuesto por los recurrentes de inconstitucionalidad de dicha medida, evidencia un tratamiento muy divergente de los sujetos que cumplieron con sus deberes tributarios respecto de aquellos que no lo hicieron ${ }^{29}$. Los primeros (aplicación de un tipo del $43 \%$ en el IRPF) contribuyen más que los segundos (10\%), habiendo observado estos un comportamiento respetuoso con la legalidad. Son tratos diversos a situaciones diferentes en los que se perjudica y hace de peor condición, al tener que tributar más, al ciudadano que cumple con sus obligaciones fiscales.

Junto a lo anterior, se ha de tener presente en la justificación de la medida las diversas perspectivas que intervienen.

En primer lugar, la obtención de una mayor recaudación. Es un efecto propio de una medida extraordinaria de crisis que pretende incrementar los ingresos públicos. En tal orientación la regularización y el gravamen que comporta prescinde, o no tiene presente, los principios inspiradores de la tributación, en particular el de igualdad en relación con el de capacidad económica. Con ello se enfatiza su fundamento extrafiscal: la obtención de ingresos como mecanismo de equilibrio de cuentas públicas, sin contemplar los principios que rigen la institución de ingresos públicos empleada. Ahora bien, tal medida extrafiscal para que sea justificable se ha de basar en principios y fines constitucionalmente protegidos -exart. 2.1. de la LGT-. ¿Cuáles son estos? Posiblemente, son los vinculados a la estabilidad presupuestaria del recientemente modificado art. 135 de

proporcionadas a dicho fin, de manera que la relación entre la medida adoptada, el resultado que se produce y el fin pretendido por el legislador superen un juicio de proporcionalidad en sede constitucional, evitando resultados especialmente gravosos o desmedidos.

${ }^{29}$ El ejemplo es el de un sujeto pasivo residente en territorio español que hubiera ocultado un millón de euros obtenidos en el desarrollo de su actividad empresarial o profesional en el año 2008 (y hubiera depositado en una cuenta bancaria en Suiza, o invertido en la compra de una finca en América). Se observa que si el sujeto declara en el año 2009 se aplica el tipo del 43\% del IRPF resultando una cuota de 430.000€. Si se aplica la amnistía en noviembre de 2012 se aplica el $10 \%$ con una cuota a pagar de $100.000 €$. 
la CE. Resulta así que la eventual justificación normativa es de un precepto modificado con motivo de la crisis económica. Nuevamente la crisis como demiurgo.

En segundo lugar, la amnistía fiscal genera una serie de efectos en la conciencia colectiva de la ciudadanía. Por un lado, desincentiva y desanima a aquellas personas que cumplieron con la legalidad tributaria y, por otro lado, incentiva y estimula conductas de ocultación, debido a la tributación premial que obtienen.

Todas estas perspectivas configuran un trato subjetivo diverso y discriminador, en donde el beneficio o privilegio establecido de la tributación puede carecer de fundamentación suficiente. La justificación suficiente resulta la clave de bóveda para apreciar la constitucionalidad de la medida; y, en definitiva, valorar la necesidad y excepcionalidad de la medida anticrisis adoptada.

\section{REFLEXIONES FinALES}

De lo analizado se observa:

En primer lugar, que la denominada amnistía fiscal es un mecanismo híbrido tributario y punitivo de carácter parcial. Por un lado, no convierte en lícitas todas las conductas derivadas de dejar de ingresar deuda tributaria -únicamente alude a concretos impuestos IRPF, IS e IRNR-. Por otro lado, su ámbito de eficacia se reduce al ámbito tributario y, respecto del punitivo, únicamente al de las sanciones administrativas. Resulta así que dicha medida no exonera de manera directa responsabilidad penal alguna, únicamente de manera indirecta en el caso del delito contra la Hacienda Pública del art. 305 del Cp en la medida que se considere existente una deuda tributaria.

En segundo lugar, es una medida extrafiscal, mira más al importe económico que supone dicha recaudación que a la vigencia de los principios de tributación. Si bien conlleva una finalidad intrínsecamente fiscal, profuturo, y en el plano de aplicación del tributo, que supone el poder controlar los bienes y derechos que se han declarado.

$\mathrm{Y}$, en tercer lugar, en la amnistía fiscal existe el peligro de que suponga premiar la ilicitud y desincentive el cumplimiento legal y puntual. Su presupuesto de aplicación es una conducta ilícita: el haber ocultado bienes, ser titular de bienes y derechos que no se correspondan con los declarados. El régimen efectuado-pago del $10 \%$ del valor de los mismos- supone un tratamiento más beneficioso que el otorgado a los contribuyentes cumplidores.

En definitiva, resulta una regulación que trata de manera singularizada y beneficiosa a los sujetos incumplidores de sus obligaciones tributarias. Se evidencia una desigualdad de trato justificada formalmente por la posibilidad de condonar deudas. Ahora bien, dicha justificación formal creemos que no es suficiente para evitar la discriminación que origina, y que lesiona el principio de igualdad constitucionalizado en el art 31.1 de la CE. En tal sentido trata de manera diversa, y de forma más favorable, a los sujetos incumplidores de las normas tributarias y eventual infractores de las mismas. 
La justificación material de tal medida -la extrafiscal de mejorar la recaudación, y la fiscal, de control futuro de los bienes declarados- no resulta suficiente ni proporcionada para su establecimiento. En el establecimiento de la medida priman los motivos extrafiscales, originando una discriminación sin fundamento suficiente en clave estrictamente tributaria. Y ante tal diatriba vuelve a planearse si la fiscalidad, y los principios que la informan, han de ceder ante exigencias no fiscales, o cuál es el grado de instrumentalidad de la norma tributaria y la virtud de sus principios.

\section{BiBLIOGRAFÍA}

Alonso L.A., "La declaración tributaria especial: luces y sombras de la 'amnistía fiscal' o el dulce sabor de la zanahoria", artículo en prensa remitido amablemente por el autor.

ANEIros, J., "La amnistía fiscal de 2012 y otras medidas que pretenden atraer capitales españoles en el exterior", en web de la Asociación Española de Asesores Fiscales 2012.

Aneiros, J., "Las obligaciones de prevención del blanqueo de capitales a cargo de determinados profesionales: una fuente de información tributaria”, Revista Técnica Tributaria, No 91. 2011.

Aneiros, J., "Las implicaciones de la normativa de prevención del blanqueo de capitales para los asesores fiscales". Documentos de la AEDAF. 2011.

Aranguez, C., El delito de blanqueo de capitales, Marcial Pons, Madrid, 2000.

Blanco, I., El delito de blanqueo de capitales. Aranzadi. Pamplona. 2002.

Cazorla, L.M., Crisis económica y transformación del Estado, Aranzadi, Navarra, 2009.

Córdoba, J. y García Aran, M., Comentarios al Código Penal. Parte especial, Tomo I, Marcial Pons, Madrid, 2004.

FALCón y Tella, R., "Las fórmulas transitorias de ‘regularización' establecidas por el RDL 12/2012, de reducción del déficit: los gravámenes especiales del $8 \%$ y del 10\%”, Quincena Fiscal, núm. 8/2012.

Ferrer, R., "Notas preliminares a la regulación fiscal de 2012: Comentarios de urgencia", en web de la Asociación Española de Asesores Fiscales 2012.

Linde, E., “Amnistía e indulto en la Constitución Española de 1978”, en Boletín Informativo del Departamento de Derecho Político e Internacional, 2. UNED, 1978-1979.

Martin, J., "Comentarios al Real Decreto-Ley 12/2012, de 30 de marzo, por el que se introducen diversas medidas tributarias y administrativas dirigidas a la reducción del déficit público", en web de la Asociación Española de Asesores Fiscales 2012.

Muñoz, F. Derecho Penal. Parte especial, Tirant lo Blanch, Valencia, 2007.

SÁNChez, M.A., Las infracciones tributarias en la nueva LGT, Marcial Pons, Madrid, 2008. 
